\title{
The acceptability and feasibility of a brief psychosocial intervention to reduce blood- borne virus risk behaviours among people who inject drugs: a randomised control feasibility trial of a psychosocial intervention (the PROTECT study) versus treatment as usual
}

Gail Gilchrist ${ }^{1 *}$, Davina Swan ${ }^{1}$, April Shaw ${ }^{2}$, Ada Keding ${ }^{3}$, Sarah Towers ${ }^{4}$, Noel Craine ${ }^{5}$, Alison Munro², Elizabeth Hughes ${ }^{6}$, Steve Parrott ${ }^{7}$, John Strang ${ }^{1}$, Avril Taylor ${ }^{2}$ and Judith Watson ${ }^{3}$

\begin{abstract}
Background: While opiate substitution therapy and injecting equipment provision (IEP) have reduced blood-borne viruses (BBV) among people who inject drugs (PWID), some PWID continue to share injecting equipment and acquire BBV. Psychosocial interventions that address risk behaviours could reduce BBV transmission among PWID.

Methods: A pragmatic, two-armed randomised controlled, open feasibility study of PWID attending drug treatment or IEP in four UK regions. Ninety-nine PWID were randomly allocated to receive a three-session manualised psychosocial group intervention and BBV transmission information booklet plus treatment as usual (TAU) ( $n=52)$ or information booklet plus TAU $(n=47)$. The intervention was developed from evidence-based literature, qualitative interviews with PWID, key stakeholder consultations, and expert opinion. Recruitment rates, retention in treatment, followup completion rates and health economic data completion measured feasibility.

(Continued on next page)
\end{abstract}

\footnotetext{
* Correspondence: gail.gilchrist@kcl.ac.uk

'Institute of Psychiatry, Psychology and Neuroscience, King's College London, Addictions Sciences Building, 4 Windsor Walk, Denmark Hill, London SE5 8BB, England, UK

Full list of author information is available at the end of the article
} 
(Continued from previous page)

Results: Fifty-six percent (99/176) of eligible PWID were recruited. More participants attended at least one intervention session in London (10/16; 63\%) and North Wales (7/13; 54\%) than in Glasgow (3/12; 25\%) and York (0/11). Participants who attended no sessions $(n=32)$ compared to those attending at least one $(n=20)$ session were more likely to be homeless (56 vs 25\%, $p=0.044$ ), injected drugs for a greater number of days (median 25 vs $6.5, p=0.019$ ) and used a greater number of needles from an IEP in the last month (median 31 vs 20, $p=0.056$ ). No adverse events were reported. 45.5\% (45/99) were followed up 1 month post-intervention. Feedback forms confirmed that the intervention was acceptable to both intervention facilitators and participants who attended it. Follow-up attendance was associated with fewer days of injecting in the last month (median $14 \mathrm{vs} 27, p=0.030$ ) and fewer injections of cocaine (13 vs 30\%, $p=0.063$ ). Analysis of the questionnaires identified several service use questionnaire categories that could be excluded from the assessment battery in a full-randomised controlled trial.

Conclusions: Findings should be interpreted with caution due to small sample sizes. A future definitive RCT of the psychosocial intervention is not feasible. The complex needs of some PWID may have limited their engagement in the intervention. More flexible delivery methods may have greater reach.

Trial registration: ISRCTN66453696

Keywords: Blood-borne virus transmission, People who inject drugs, Feasibility randomised controlled trial, Psychosocial interventions, Focus group research

\section{Background}

Studies report the prevalence of Hepatitis $\mathrm{C}$ virus $(\mathrm{HCV})$ among people who inject drugs (PWID) ranges from 5 to $90 \%$ [1] and the prevalence of HIV ranges from $<1$ to $50 \%$ [2]. In the UK, HCV is the most prevalent bloodborne virus (BBV) among PWID, with $23-61 \%$ being HCV positive $[1,3]$; the rates of human immunodeficiency virus (HIV) and hepatitis B (HBV) among PWID in the UK are much lower, $0-1.4 \%$ for HIV and $6-18 \%$ for HBV [3] preventing the transmission of BBV among PWID thus remains a major public health issue.

While HBV and HIV are transmitted via blood or body fluids, the greatest risk of $\mathrm{HCV}$ transmission among PWID is via blood from sharing needles and other injection paraphernalia $[4,5]$. Advances have been made in treatment and pre-exposure prophylaxis for $\operatorname{HIV}[6,7]$, and a vaccine is available for HBV [8]; however, there is currently no vaccine available to prevent $\mathrm{HCV}$ infection. Opiate substitution therapy and injecting equipment provision (IEP) have been shown to be effective in reducing HIV and HCV among PWID [9-12]; and psychosocial interventions (such as brief interventions, motivational interviewing, cognitive behavioural therapy and contingency management) could further decrease BBVs [10] by educating PWID about transmission risks and developing strategies to avoid them.

Research suggests there is a gap in knowledge among PWID regarding HCV transmission which is contributing to the high prevalence [13-15], among both new and longer term injectors. PWID with mental health issues report greater sharing of injection equipment, lower rates of condom use, multiple sexual partners, sex trading and having sex with PWID [16-19].
Public Health England's Shooting Up report [20] highlighted that in 2015 in England, Wales and Northern Ireland, sharing of needles in the previous month was reported by $16 \%$ of individuals attending drug treatment services, in Scotland this figure was 15\% in 2014-2015. The report highlighted that the sharing of mixing containers and filters was almost twice as common as the sharing of needles and syringes. A large UK survey has also identified an increased risk of infection for those who inject amphetamines and amphetamine-type drugs, such as mephedrone [21]. Therefore, reducing BBV transmission risk behaviours among PWID remains a priority.

A recent meta-analysis found that interventions using strategies that combined substance-use treatment and support for safe injection were most effective at reducing HCV seroconversion [22]. A number of recent systematic reviews of psychosocial interventions (e.g. skills training, peer-education training and counselling) compared to lesser interventions or educational interventions to reduce HIV and $\mathrm{HCV}$ injecting and sexual risk behaviours among PWID have reported modest effects [23, 24], concluding that future research should determine whether these interventions work better for particular groups of drug users [23] and that "multi-component interventions are required" [24].

A psychosocial intervention (the PROTECT intervention) to reduce BBV transmission risk behaviours and increase BBV transmission knowledge among PWID was developed, and a feasibility randomised controlled trial (RCT) comparing the psychosocial intervention to an information leaflet, to demonstrate the feasibility and acceptability of delivering the intervention in harm reduction settings throughout the UK was conducted. 


\section{Methods}

\section{Study design}

A pragmatic, two-armed, randomised controlled, open feasibility study in which a psychosocial group (brief) intervention was compared to treatment as usual (TAU) plus information leaflets, on reducing the BBV transmission risk behaviours for PWID aged $\geq 18$ years. Ethical approval was granted by the National Research Ethics Committee East Midlands-Leicester South Research Ethics Committee (Reference: 15/EM/0413). Local Research and Development (R\&D) approval was obtained, as was agreement to participate from the relevant services.

\section{Setting}

The trial was conducted in four locations across the UK: in England (London, York), Wales (North Wales) and Scotland (Glasgow). A mix of urban and semi-rural community services/sites were included to ensure different modes of service delivery were represented:

1. London: Three Drug and Alcohol Treatment Services providing services including advice and IEP and treatment to people, aged over 18, who have drug- and/or alcohol-related problems, including a prescribing clinic within a hostel for homeless people. The intervention was delivered at one Drug and Alcohol Treatment Service.

2. York: Participants were recruited, and the intervention was scheduled to be delivered at a city centre substance use treatment service providing counselling and advice, IEP, condoms, assessment and referral to residential rehabilitation, specialist drug units and other agencies providing treatment for addiction and BBV testing.

3. Glasgow: Participants were recruited from and the intervention delivered in a drugs treatment service in the city centre which provides both treatment and IEP.

4. North Wales: Participants were recruited from a drug service, a drop-in centre and IEP for homeless people and a mobile harm reduction service for PWID not currently engaged in treatment. The intervention was delivered at the drop-in centre and IEP for homeless people.

\section{Participants}

\section{Identification, eligibility and consent}

Potential participants were approached by researchers in the waiting rooms of participating services and given a Participant Information Sheet that was also explained to them verbally. Key workers and IEP workers also referred eligible clients to the researchers. In addition, flyers were distributed and posters were displayed in the services, inviting interested participants to contact the researcher for more details about the study. All interested clients were screened for eligibility. Clients were eligible if they were aged $\geq 18$ years, had injected drugs (other than performance enhancing drugs) at least once in the past 4 weeks, planned to stay in the area for the next 3 months, were able to complete the assessments (all assessments were researcher administered) and could communicate in a group intervention in English. They were excluded if they were too intoxicated to give informed consent or were noticeably in withdrawal. If eligible and interested, written informed consent was obtained.

\section{Outcome Measures}

Self-reported age, recent drug use, length of injecting career, drug treatment history, HIV and Hepatitis C status and vaccination against Hepatitis $B$ were recorded.

\section{Recruitment and acceptability}

Recruitment rates (i.e. number agreeing to participate/ number eligible), retention in treatment (number of sessions attended) and follow-up questionnaires completion rates measured feasibility. Acceptability to participants was ascertained through feedback forms and separate focus group discussions with participants and facilitators.

\section{Patient-reported outcomes}

Participants received $£ 10$ cash (London) or $£ 10$ gift voucher (York, Glasgow, North Wales) for time involved in completing baseline and follow-up questionnaires. Travel reimbursement was available in London and North Wales. Demographic data were collected at baseline, and the following outcome measures were collected at baseline, at the end of intervention and 1 month post-intervention (intervention arm), and equivalent time period for control arm:

Injecting risk behaviours and self-efficacy

Nine injecting risk behaviours were assessed during the past 28 days (including passing any needles or syringes, cleaned needles or syringes, spoons or containers for mixing, or filters to someone else after using them; using any needle or syringes, cleaned needles or syringes, spoons or containers for mixing, or filters previously used by someone else; sharing rinse water) that may have exposed them to BBV in the previous month were assessed using questions from Public Health England's survey of PWID [3]. Events were summed to a total ranging from 0 (engaged in no risk events) to 9 (engaged in all of the risk events). Participants indicated agreement with eight self-efficacy questions around injecting behaviours, e.g. "I can avoid sharing a needle even if I am in withdrawal", around injecting skills (including finding a vein, sharing equipment, cleaning equipment and talking about safe drug use) [25]. Agreement was rated between 1 (absolutely cannot) and 4 (absolutely can), with total scores between 8 (low self-efficacy) and 32 (high self-efficacy) [25]. 
Sexual risk behaviours

Having had sex with more than one partner in the past month, not always having used a condom when having sex in the past month, four items assessed whether participants were not "absolutely sure" they would use a condom in a given situation (sex with a regular partner, even if they do not want to use one or participant had been using alcohol or drugs; sex with a casual partner, even if they do not want to use one or participant had been using alcohol or drugs) and one question on whether they would be able to talk about safe sex with sexual partners they did not know. These seven items were summed to a total ranging from 0 (no risk behaviours) to 7 (all risk behaviours).

Withdrawal Prevention Tactics scale This five-item scale asked whether participants had done any of four listed tactics to avoid withdrawal episodes: saved a bag for the next morning, put aside additional drugs, stored methadone or put aside money for getting the next bag in an emergency [26]. A fifth item asked about use of other substances, such as painkillers, to avoid withdrawal symptoms until they are able to obtain their drug of choice. The frequency of undertaking each withdrawal activity in the past month were collected with responses ranging from 0 (never) to 4 (very often). The total score ranged from 0 (never taken any of the preventative actions) to 20 (taken preventative actions very often for all of the activities).

\section{BBV transmission knowledge}

Participants rated 14 statements about HIV transmission [27], 31 about $\mathrm{HCV}$ transmission [28, 29] and 15 about HBV [30]. The total number of correct answers across each BBV transmission questionnaire was summed (range 0-14 for HIV, 0-31 for HCV and 0-15 for HBV).

Motivation to change behaviour

Participants were asked to rate their motivation from 1 (not at all motivated) to 5 (extremely motivated) to protect themselves and others from acquiring BBV.

Health-related quality of life (HRQoL)

The European quality of life- 5 dimensions- 5 levels (EQ-5D-5L) characterised health on five dimensions (mobility, self-care, ability to undertake usual activities, pain, anxiety/depression) [31].

Health and social resource used Hospital and primary health care services use, drug service use, other health-related services, contact with the police and criminal justice system, and medications prescribed in the past month were recorded.

\section{Sample size}

We aimed to recruit a total of 128 participants (64 in intervention group) from harm reduction services in 4 locations (Glasgow, London, York and North Wales), exceeding that recommended for feasibility studies of between 24 and 50 [32-34] and allowed feasibility assessments within both community clinics and IEP.

\section{Randomisation process}

Treatment allocation was performed by a secure, remote, telephone randomisation service based at the University of York. Participants were randomised by stratified block randomisation, ensuring balanced allocation within each location, setting (community drug service or IEP) and gender. Participants were randomised to either:

- The psychosocial group intervention, information booklets plus TAU or

- The control arm: information booklets plus TAU only

\section{Intervention and comparator}

The PROTECT intervention was co-developed by service users, service providers, policy makers and academics based on an evidence-based literature, qualitative interviews with PWID, consultation with key stakeholders and expert opinion. The PROTECT manual is available for download free of charge via: https:// www.kcl.ac.uk/ioppn/depts/addictions/research/drugs/ bloodborneviruses.aspx. The manualised psychosocial group intervention consisted of three, one hour sessions (preferably, one a week for three consecutive weeks). Session 1 covered improving injection skills and good vein care. Session 2 covered planning for risk situations. Session 3 provided information about blood-borne viruses and transmission risk behaviours. Sessions used videos, games and exercises to facilitate discussion and build skills and strategies to reduce and avoid risk. All sessions also included a didactic education section. Separate groups were held for women and men.

The structure of drug treatment services was different across the settings in the study; the precise job role of the health care professionals who conducted the groups thus varied. However, in all settings, groups were facilitated by professionals with considerable experience of working with PWID and BBV. Training took place with all facilitators in London over 1 day and was co-delivered by a clinician and peer educator. Following training, intervention delivery varied across sites to reflect current service provision: London-the group was co-facilitated by a drug worker and peer educator (gender of co-facilitators matched that of the gender of the group); Glasgow-groups were co-facilitated by one male drug worker and one female project co-ordinator; North Wales-the groups were co-facilitated by one male and one female drug worker; and 
York-the groups were due to be delivered by one male nurse specialising in BBV prevention and treatment. Contingency management was used to retain participants in the intervention [35]. Participants allocated to the intervention arm received $£ 10$ cash (London) or $£ 10$ gift voucher (Glasgow and North Wales) for each of the three sessions attended. A "bonus" of $£ 10$ cash (London) or $£ 10$ gift voucher (Glasgow and North Wales) was given to those who attended all three sessions.

Intervention evaluation/fidelity All sessions were observed by at least one researcher to assess the feasibility of the quality assurance methods proposed for the main trial, including acceptability to drug worker/nursing staff and service users. A brief checklist was used to identify what aspects of the intervention manual were implemented. At the end of each session, facilitators and participants rated the session using an evaluation form developed for the study.

\section{Control}

Participants in both arms received TAU from the service from which they were recruited and a booklet containing information on Hepatitis C ("Hep C Info: Understanding hepatitis $C$ and staying safe" http://ljwg.org.uk/ljwg-tool $\mathrm{kit} /$ resources/) and a one-page information sheet developed specifically for the trial about a recent HIV outbreak among PWID.

\section{Analyses}

All analyses were conducted using Stata Version 13.1. Feasibility parameters were reported descriptively and participant flow is illustrated with a flow diagram [Fig. 1: Study flow diagram]. Following observed differences in compliance and follow-up at the four sites, population characteristics for these groups were compared using Fisher's Exact and Wilcoxon rank-sum tests. As a feasibility trial, the study was not powered for formal testing of intervention effectiveness; however, group differences for selected outcome measures were explored as follows. Longitudinal regression analyses for each outcome at the two follow-up points were conducted, adjusting for baseline values, gender and recruitment site. Estimated mean treatment group differences from these analyses are presented by intention to treat (ITT) and per protocol groups together with 80 and $95 \%$ confidence intervals.

The economic analysis included intervention costing, calculation of NHS and wider social costs per patient, EQ-5D-5 L results and assessment of the pilot questionnaires. Quantities of service use recorded were multiplied by national average unit costs of health care and criminal justice contacts to derive a health care cost (price year 2014/5). Follow-up costs were defined by summing costs at the end of the intervention and one month post-intervention.

\section{Results}

\section{Feasibility parameters}

Feasibility was assessed as the proportion of patients consented and randomised, as well as compliance with the intervention and attrition throughout follow-up.

The flow of participants is shown in Fig. 1 [Fig. 1: Study flow diagram]. Of 176 eligible people who injected drugs, 99 (56\%) individuals were randomised into the feasibility trial during January and February 2016. One person was mistakenly randomised twice (therefore, 100 randomisations); their second randomisation was subsequently withdrawn.

It was not possible to compare those who were eligible that did and did not agree to participate. The eligibility question asked whether potential participants had injected drugs in the previous month. If they had, researchers discussed the study with potential participants and what taking part involved. Seventy-seven of the 176 eligible participants (44\%) did not take part as they were not interested, too busy, entering rehabilitation treatment, too ill to participate, unavailable to attend interventions, not wishing others to know about their injecting, declined without reason, or were uncontactable or did not attend their baseline appointment.

Fifty-two were allocated to the intervention arm and 47 allocated to control. A total of 20 participants attended at least one intervention session, and just under half of participants were followed up until 1 month post-intervention. Two female participants in London were in hospital, one male participant was in prison in North Wales, and in Glasgow, three female and three male participants were in residential rehabilitation, one male participant was in prison and one male participant was in hospital. It was not possible to conduct follow-up interviews with those participants.

Attendance for at least one intervention session was highest in London (63\%) and North Wales (54\%), whereas only $25 \%$ attended in Glasgow, and no participants attended in York. Follow-up at a minimum of one time point (at the end of the intervention or one month post-intervention) was also highest in London (83\%) and North Wales (63\%) and significantly lower in Glasgow (55\%) and York (43\%). Overall, men were more likely to attend at least one intervention session (44 versus $28 \%$ ). Women were more likely to attend follow-up in London (85\%) than in York (38\%), North Wales (38\%) and Glasgow (17\%).

\section{Baseline characteristics}

Overall, participants were predominantly male, in their late 30s/early 40s with a mean injecting history of between 14 and 21 years (data aggregated by gender). Baseline characteristics of the trial population by allocation and sex are presented in Table 1. Baseline characteristics were 


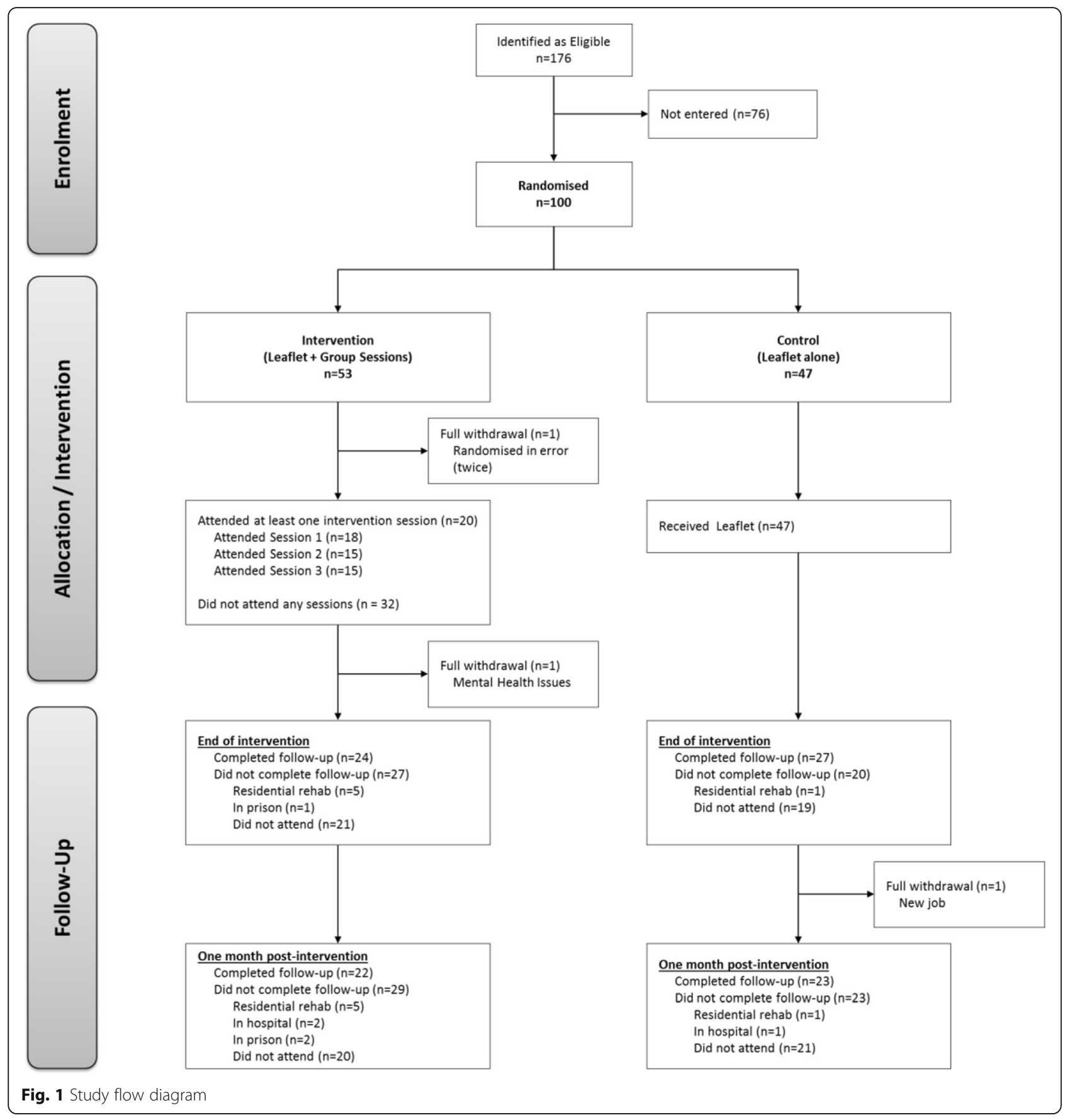

comparable between randomised treatment groups for males, despite the relatively small number of participants. The smaller group of women showed potential imbalances, e.g. a greater number of heroin users and homeless women in the intervention arm.

Compared to those who attended at least one intervention session $(n=20)$, those who did not attend any sessions $(n=32)$ were more likely to be homeless (56 vs $25 \%, p=0.044$ ), have injected drugs for a greater number of days in the last month (median 25 vs $6.5, p=0.019$ ) and used a greater number of needles from an IEP in the last month (median 31 vs $20, p=0.056$ ). They were more likely to be predominant heroin injectors (69 vs $40 \%, p=0.055$ for type of drug) and less likely to inject crack ( 31 vs $55 \%, p=0.146$ ) [Additional file 1]. Glasgow and York had higher levels of homelessness (68 and 52\% respectively) compared to London (27\%) and North Wales (29\%). In addition, participants injected for a greater number of days and used more needles from an IEP [Additional file 2]. 
Table 1 Baseline characteristics by allocation and gender

\begin{tabular}{|c|c|c|c|c|}
\hline & \multicolumn{2}{|l|}{ Male } & \multicolumn{2}{|l|}{ Female } \\
\hline & $\begin{array}{l}\text { Intervention } \\
N=34\end{array}$ & $\begin{array}{l}\text { Control } \\
N=30\end{array}$ & $\begin{array}{l}\text { Intervention } \\
N=18\end{array}$ & $\begin{array}{l}\text { Control } \\
N=17\end{array}$ \\
\hline \multicolumn{5}{|l|}{ Age } \\
\hline Mean (SD) & $41.7(6.81)$ & $41.4(7.30)$ & $35.8(6.06)$ & $37.9(8.79)$ \\
\hline Median & 42.5 & 42 & 35 & 37 \\
\hline Min, max & 26,57 & 22,54 & 26,48 & 26,62 \\
\hline \multicolumn{5}{|l|}{ Number of years injecting } \\
\hline Mean (SD) & $21.4(8.00)$ & $19.5(9.01)$ & $11.9(7.58)$ & $16.1(12.14)$ \\
\hline Median & 22 & 19 & 11.5 & 14 \\
\hline Min, max & 3,36 & 1,42 & 0,34 & 0,44 \\
\hline Used injecting equipment provision (IEP) in the last month & $31(91.2 \%)$ & $26(86.7 \%)$ & $16(88.9 \%)$ & $16(94.1 \%)$ \\
\hline Detox/maintenance drug use & $26(76.5 \%)$ & $26(86.7 \%)$ & 17 (94.4\%) & $16(94.1 \%)$ \\
\hline \multicolumn{5}{|l|}{ Most frequently injected drug } \\
\hline Heroin & $15(44.1 \%)$ & $23(76.7 \%)$ & $15(83.3 \%)$ & $10(58.8 \%)$ \\
\hline Crack & $1(2.9 \%)$ & $2(6.7 \%)$ & $0(0.0 \%)$ & $0(0.0 \%)$ \\
\hline Cocaine & $4(11.8 \%)$ & $1(3.3 \%)$ & $0(0.0 \%)$ & $1(5.9 \%)$ \\
\hline Heroin and crack & $8(23.5 \%)$ & $2(6.7 \%)$ & $3(16.7 \%)$ & $3(17.6 \%)$ \\
\hline Heroin and cocaine & $1(2.9 \%)$ & $0(0.0 \%)$ & $0(0.0 \%)$ & $1(5.9 \%)$ \\
\hline Heroin and amphetamine & $0(0.0 \%)$ & $0(0.0 \%)$ & $0(0.0 \%)$ & $1(5.9 \%)$ \\
\hline Speedball & $1(2.9 \%)$ & $0(0.0 \%)$ & $0(0.0 \%)$ & $0(0.0 \%)$ \\
\hline Amphetamine & $3(8.8 \%)$ & $2(6.7 \%)$ & $0(0.0 \%)$ & $1(5.9 \%)$ \\
\hline Methadone, M-cat & $1(2.9 \%)$ & $0(0.0 \%)$ & $0(0.0 \%)$ & $0(0.0 \%)$ \\
\hline Homeless & $15(44.1 \%)$ & $14(46.7 \%)$ & $8(44.4 \%)$ & $5(29.4 \%)$ \\
\hline HIV Positive & $1(2.9 \%)$ & $0(0.0 \%)$ & $0(0.0 \%)$ & $0(0.0 \%)$ \\
\hline Hepatitis C Positive & $17(50 \%)$ & $15(50 \%)$ & $5(27.8 \%)$ & $6(35.3 \%)$ \\
\hline Hepatitis B vaccinated & 27 (79.4\%) & 22 (73.3\%) & 18 (100\%) & 14 (82.4\%) \\
\hline
\end{tabular}

Follow-up attendance (at one or both time points) was associated with fewer days of injecting drugs in the last month (median 14 vs $27, p=0.030$ ) and fewer injections of cocaine (13 vs $30 \%, p=0.063$ ).

\section{Outcome measures}

Outcome measures are summarised by randomised allocation in Table 2 (total) and Table 3 (compliance).

The summary of group differences based on the exploratory longitudinal regression analyses for each outcome (Table 4) revealed improved (fewer) injecting risk practices, improved self-efficacy, better hepatitis C and hepatitis B transmission knowledge and greater use of withdrawal prevention techniques in the intervention arm. Little change for any group was seen for HIV transmission knowledge. A number of results appeared counterintuitive. Participants in the randomised intervention group engaged in a greater number of sexual risk behaviours at both follow-up time points, although group differences were reduced to minimal in the attendance-based analysis. Motivation to change was highly skewed, with most participants indicating being highly motivated.

Sample sizes were too small to investigate possible interactions with baseline characteristics and outcomes, e.g. whether score changes can only be seen in a subset of the participant population.

All outcome measures were reviewed with regard to the number of missing items that contribute to each outcome. Overall, data completeness was very high across all questionnaires responses, and most items were only missing sporadically.

At 1 month post-intervention, no increase in self-reported injecting in more "risky" sites (e.g. groin, neck) was observed among participants who had attended at least one session of the intervention. A trend towards injecting on fewer days in the past 28 days for those who had attended at least one session at 1 month post-intervention was seen. Therefore, exposure to sessions on improving injecting techniques as part of BBV harm reduction psychosocial intervention does not appear to encourage riskier injecting practices or frequency of injecting. 
Table 2 Trial outcomes (total—groups as randomised)

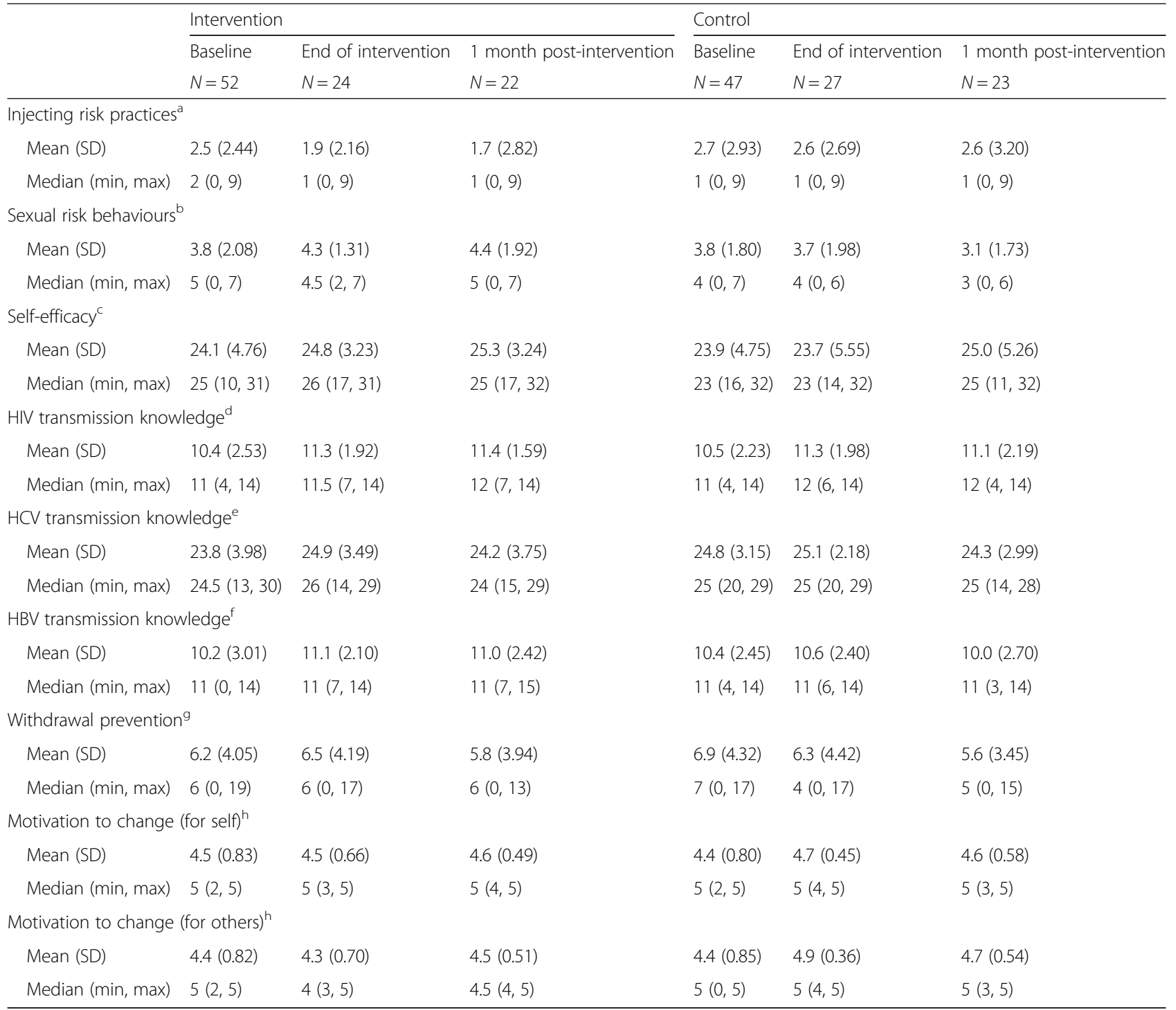

${ }^{a}$ Range: 0-9 (higher number $=$ more risk events)

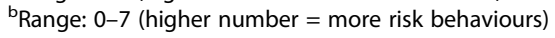

'Range: 8-32 (higher score $=$ greater self-efficacy)

dRange: 0-14 (higher score = better knowledge)

e Range: 0-31 (higher score = better knowledge)

fRange: 0-15 (higher score = better knowledge)

${ }^{9}$ Range: 0-20 (higher score $=$ better prevention tactics)

${ }^{\text {h}}$ Range: $0-5$ (higher score $=$ more motivation)

No adverse events were recorded as a result of participating in the feasibility trial.

\section{Health economics}

\section{Service use questionnaire}

Analysis of the questionnaires identified several categories that could be excluded from the assessment battery in a full-randomised controlled trial. Twelve service use categories of cost were identified where $>90 \%$ of responses at all three contacts were zero. The results allow questionnaires to be revised for future use.
Costs for sessions 1, 2 and 3 are estimated for each of the treatment centres (Table 5). Cost per patient is attributed to the attendee and then the cost per session summed to derive a total treatment cost. Total patient treatment costs are derived by summing the costs of the sessions attended (maximum $=3$ ).

Mean cost was $£ 58.17$ for patients attending one session, $£ 148.54$ for those attending two sessions and $£ 270.67$ for those attending all three sessions in the intervention group. Control cost per patient was $£ 0.86$. In a pragmatic setting, these sessions would be 
Table 3 Trial outcomes (total—groups by compliance)

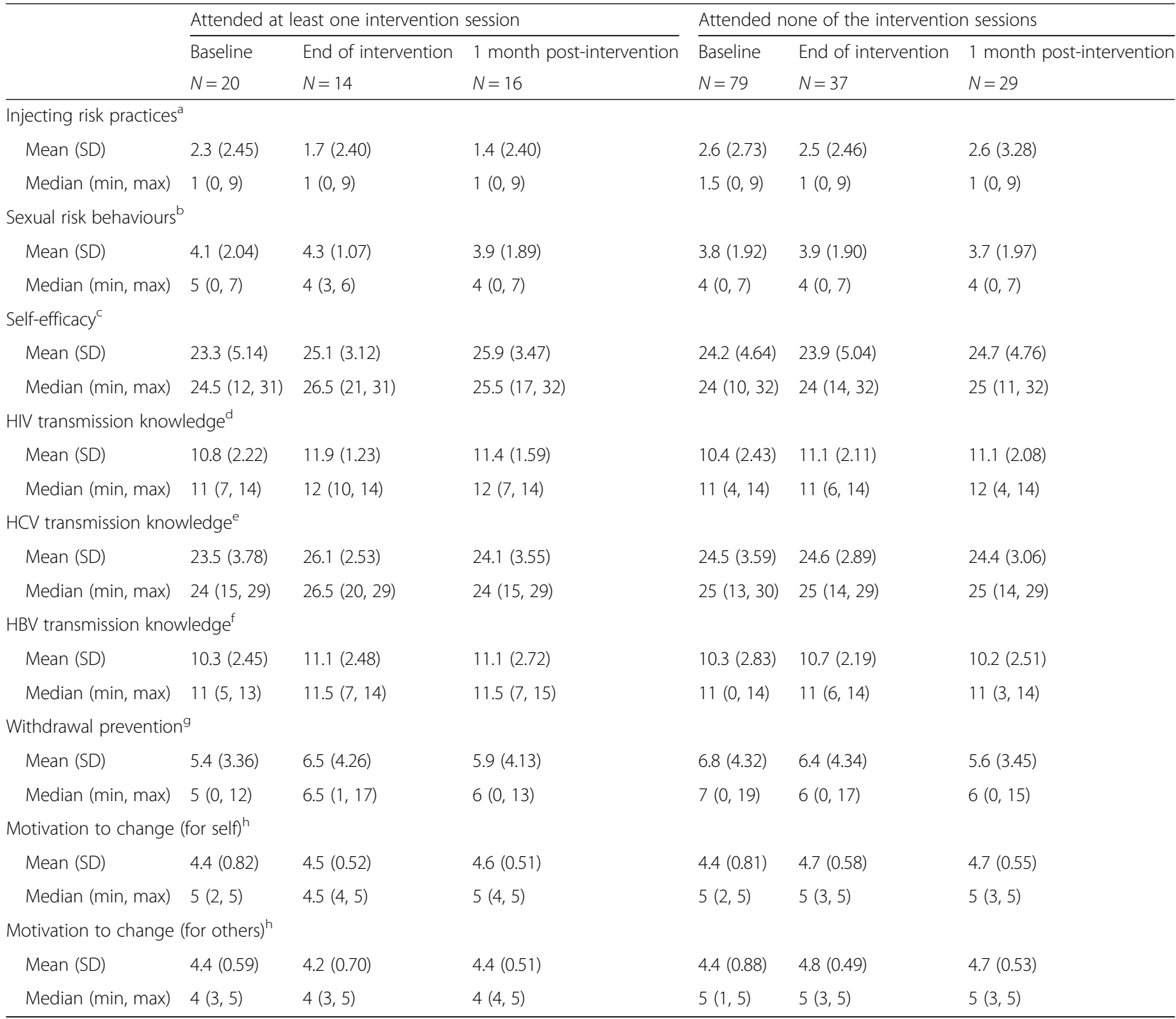

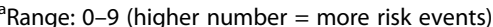

${ }^{\mathrm{b}}$ Range: $0-7$ (higher number $=$ more risk behaviours)

'Range: 8-32 (higher score $=$ greater self-efficacy)

${ }^{\mathrm{d}}$ Range: 0-14 (higher score $=$ better knowledge)

${ }^{e}$ Range: 0-31 (higher score $=$ better knowledge)

fRange: 0-15 (higher score $=$ better knowledge)

${ }^{9}$ Range: $0-20$ (higher score $=$ better prevention tactics)

${ }^{h}$ Range: $0-5$ (higher score $=$ more motivation)

delivered to more patients, thus reducing the mean per session training cost.

\section{Health-related quality of life}

EQ-5D-5 L scores were valued using the social tariff [36] at the three time points using paired analysis (Table 6). The tariff provides utility values from a population survey whereby values for each health state are given a utility score; hence, these scores reflect the population preferences for health state values.
Baseline and control showed increases in scores on EQ-5D-5L across the time period. EQ-5D-5L scores in both groups improved from baseline through the two follow-ups showing potential for health improvement and associated QALY gains. Differences between groups should be treated with caution due to the small sample size. Differences in the changes between groups were not significant, for the change baseline to the end of the intervention the mean difference between groups was 0.05 (95\% CI: $-0.08,0.17)$ and from end of the intervention to 1 month post-intervention the difference between 
Table 4 Summary of mean group differences for outcome measures ${ }^{i}$

\begin{tabular}{|c|c|c|c|c|c|c|c|}
\hline & & \multicolumn{3}{|c|}{ Analysis by randomised groups (ITT) } & \multicolumn{3}{|c|}{$\begin{array}{l}\text { Analysis by attendance of at least one } \\
\text { intervention session }\end{array}$} \\
\hline & & Mean & $95 \% \mathrm{Cl}$ & $80 \% \mathrm{Cl}$ & Mean & $95 \% \mathrm{Cl}$ & $80 \% \mathrm{Cl}$ \\
\hline \multirow[t]{2}{*}{ Injecting risk practices ${ }^{a}$} & End of intervention & -0.45 & -1.50 to 0.61 & -1.14 to 0.24 & -0.52 & -1.78 to 0.74 & -1.35 to 0.30 \\
\hline & 1 month post-intervention & -0.25 & -1.33 to 0.82 & -0.96 to 0.45 & -0.25 & -1.51 to 1.01 & -1.08 to 0.57 \\
\hline \multirow[t]{2}{*}{ Sexual risk behaviours ${ }^{\mathrm{b}}$} & End of intervention & 0.57 & -0.20 to 1.34 & 0.06 to 1.07 & 0.08 & -0.85 to 1.02 & -0.53 to 0.70 \\
\hline & 1 month post-intervention & 1.26 & 0.43 to 2.08 & 0.71 to 1.80 & 0.13 & -0.80 to 1.06 & -0.48 to 0.74 \\
\hline \multirow[t]{2}{*}{ Self-efficacy ${ }^{c}$} & End of intervention & 1.17 & -0.71 to 3.05 & -0.06 to 2.40 & 2.20 & 0.02 to 4.38 & 0.77 to 3.62 \\
\hline & 1 month post-intervention & 0.08 & -1.90 to 2.07 & -1.22 to 1.38 & 1.65 & -0.51 to 3.82 & 0.24 to 3.07 \\
\hline \multirow[t]{2}{*}{ HIV transmission knowledge ${ }^{d}$} & End of intervention & -0.06 & -0.88 to 0.75 & -0.60 to 0.47 & 0.04 & -0.91 to 0.99 & -0.58 to 0.66 \\
\hline & 1 month post-intervention & 0.18 & -0.70 to 1.06 & -0.39 to 0.76 & -0.07 & -1.00 to 0.87 & -0.68 to 0.55 \\
\hline \multirow[t]{2}{*}{ HCV transmission knowledge } & End of intervention & 0.16 & -1.37 to 1.68 & -0.84 to 1.15 & 2.13 & 0.41 to 3.85 & 1.01 to 3.26 \\
\hline & 1 month post-intervention & 0.12 & -1.52 to 1.75 & -0.96 to 1.19 & 0.30 & -1.40 to 1.99 & -0.81 to 1.41 \\
\hline \multirow[t]{2}{*}{ HBV transmission knowledge ${ }^{f}$} & End of intervention & 0.79 & -0.31 to 1.89 & 0.07 to 1.51 & 0.79 & -0.51 to 2.08 & -0.06 to 1.63 \\
\hline & 1 month post-intervention & 0.75 & -0.41 to 1.91 & -0.01 to 1.51 & 0.88 & -0.41 to 2.18 & 0.03 to 1.73 \\
\hline \multirow[t]{2}{*}{ Withdrawal prevention ${ }^{9}$} & End of intervention & 0.28 & -1.37 to 1.93 & -0.80 to 1.36 & 0.38 & -1.54 to 2.31 & -0.88 to 1.64 \\
\hline & 1 month post-intervention & 1.41 & -0.34 to 3.17 & 0.26 to 2.57 & 1.83 & -0.10 to 3.76 & 0.57 to 3.09 \\
\hline \multirow[t]{2}{*}{ Motivation to change $(\text { for self })^{h}$} & End of Intervention & -0.20 & -0.47 to 0.07 & -0.38 to -0.03 & -0.21 & -0.52 to 0.09 & -0.42 to -0.01 \\
\hline & 1 month post-intervention & -0.01 & -0.30 to 0.28 & -0.20 to 0.18 & -0.21 & -0.51 to 0.10 & -0.41 to -0.01 \\
\hline \multirow[t]{2}{*}{ Motivation to change (for others) ${ }^{h}$} & End of intervention & -0.40 & -0.67 to- -0.13 & -0.58 to -0.22 & -0.53 & -0.84 to -0.23 & -0.73 to -0.33 \\
\hline & 1 month post-intervention & -0.14 & -0.43 to 0.15 & -0.33 to 0.05 & -0.29 & -0.59 to 0.01 & -0.49 to -0.10 \\
\hline
\end{tabular}

anange: 0-9 (higher number = more risk events)

${ }^{\mathrm{b}}$ Range: 0-7 (higher number $=$ more risk behaviours)

'Range: 8-32 (higher score = greater self-efficacy)

${ }^{\mathrm{d}}$ Range: $0-14$ (higher score $=$ better knowledge)

e Range: 0-31 (higher score = better knowledge)

fRange: 0-15 (higher score = better knowledge)

${ }^{9}$ Range: 0-20 (higher score = better prevention tactics)

hange: $0-5$ (higher score $=$ more motivation)

'Mean differences represent the estimated mean group difference following regression analysis adjusted for outcome at baseline, gender and recruitment site;

Positive mean difference $=$ higher score in the intervention arm, negative mean difference $=$ higher score in the control arm

groups was 0.11 (95\% CI: $-0.11,0.32)$. We do not present quality-adjusted life years due to the short follow-up and the expectation that health utility gains would become evident over a period longer than 1 month.

\section{Health and social resources used}

Although wider NHS costs, social costs and criminal justice costs also showed a reduction from baseline through follow-up periods, there were no significant differences between groups at any time point (Table 7). Health care and criminal justice costs were also assessed at baseline and follow-up by compliance, but there were no significant differences based on whether a patient had attended one or more treatment sessions compared to those who had attended no sessions.

\section{Acceptability of the PROTECT intervention}

Intervention group participants who attended the PROTECT sessions rated the sessions highly, reporting they had gained valuable knowledge on blood-borne virus transmission, safer drug use, hygiene and handwashing, cleaning equipment and preparing for risk situations such as withdrawal. To improve the PROTECT intervention, participants suggested making it more visual, interactive and incorporating more practical instruction around injecting technique and injecting sites. It was also suggested that the videos illustrating the side effects of injecting should be more graphic and feature real people rather than animations.

Facilitators who delivered the PROTECT intervention suggested delivering the training event over 2 days, with equal time devoted to each of the three PROTECT sessions, incorporating opportunities for mock delivery. They appreciated peer educators being involved in the training event and that their input had been incorporated into the final version of the PROTECT manual. The sessions were rated highly and being involved in the intervention had improved knowledge and led to changes in their practice with clients from IEP. Session 1 was thought too lengthy and facilitators were less comfortable delivering the didactic parts and discussing sexual risk behaviour. Making the intervention more interactive and 
Table $\mathbf{5}$ Intervention and control costs per session by centre

\begin{tabular}{|c|c|c|c|c|}
\hline \multicolumn{5}{|c|}{ Intervention session costs } \\
\hline & Total cost & $\begin{array}{l}\text { Patients } \\
\text { attending }\end{array}$ & $\begin{array}{l}\text { Cost per } \\
\text { patient }\end{array}$ & $\begin{array}{l}\text { Cost excl. } \\
\text { training }\end{array}$ \\
\hline \multicolumn{5}{|l|}{ London } \\
\hline Session 1 & $£ 349.02$ & 6 & $£ 58.17$ & $£ 30.21$ \\
\hline Session 2 & $£ 333.35$ & 5 & $£ 66.67$ & $£ 33.12$ \\
\hline Session 3 & $£ 333.20$ & 5 & $£ 66.64$ & $£ 33.09$ \\
\hline \multicolumn{5}{|l|}{ London (2) } \\
\hline Session 1 & $£ 316.56$ & 2 & $£ 158.28$ & $£ 74.39$ \\
\hline Session 2 & $£ 323.43$ & 3 & $£ 107.81$ & $£ 51.89$ \\
\hline Session 3 & $£ 316.44$ & 2 & $£ 158.22$ & $£ 74.33$ \\
\hline \multicolumn{5}{|l|}{ Scotland } \\
\hline Session 1 & $£ 310.83$ & 3 & $£ 103.61$ & $£ 47.69$ \\
\hline Session 2 & $£ 310.38$ & 3 & $£ 103.46$ & $£ 47.54$ \\
\hline Session 3 & $£ 308.80$ & 2 & $£ 154.40$ & $£ 70.51$ \\
\hline \multicolumn{5}{|l|}{ Wales } \\
\hline Session 1 & $£ 318.48$ & 6 & $£ 53.08$ & $£ 25.11$ \\
\hline Session 2 & $£ 313.16$ & 4 & $£ 78.29$ & $£ 36.55$ \\
\hline Session 3 & $£ 319.38$ & 6 & $£ 53.23$ & $£ 53.23$ \\
\hline \multicolumn{5}{|l|}{ Control cost } \\
\hline \multicolumn{2}{|l|}{ Cost item } & & \multicolumn{2}{|l|}{ Unit cost } \\
\hline \multicolumn{2}{|l|}{ Staff time } & & \multicolumn{2}{|l|}{$£ 0.81$} \\
\hline \multicolumn{2}{|l|}{ Leaflet } & & \multicolumn{2}{|l|}{$£ 0.05$} \\
\hline \multicolumn{2}{|c|}{ Cost per patient } & & \multicolumn{2}{|l|}{$£ 0.86$} \\
\hline
\end{tabular}

including specialist workers for specific components (e.g. injecting instructors, BBV nurses or sexual health practitioners) were suggested improvements. Other potential modes of delivery were delivery in bite-size pieces to clients, developing as an app or QR scanner, or as an online resource for staff training. Preparedness plans could also be incorporated into clients' care plans. Identified key target groups were new referrals to treatment, new injectors, sex workers, people who inject who engage in chemsex, ie. the use of drugs (most commonly crystal methamphetamine, mephedrone and gammaydroxybutrate/gamma-butyrolactone), by men who have sex with men to facilitate or enhance sexual activity.

\section{Discussion}

We explored the feasibility of a three-session, genderspecific psychosocial group intervention to reduce BBV transmission behaviours among PWID which included skills to improve injecting techniques and thus vein care, and strategies to avoid and plan for risk situations that PWID had themselves identified within in-depth interviews undertaken to inform the intervention development (see the "Methods" section).

Although the resultant intervention was acceptable to both facilitators and attending participants and 57\% of eligible participants agreed to be randomised, suggesting support for addressing BBV risk behaviours among PWID, there were considerable difficulties recruiting particular groups of PWID, mainly women and new injectors. One potential way to improve recruitment could have been to use chain or snowball sampling, rather than researcher recruitment, where recruited participants are encouraged to recruit members of their networks to the study. A previous survey in Wales suggested individuals whose main source of needles and syringes was secondary distribution were more likely to be younger and more recent onset injectors; this might explain the difficulty in recruiting newer and younger injectors [37]. Research suggests that women are more likely than men to face additional barriers to accessing and attending treatment for drug use including family and childcare responsibilities, shame or fear that their children will be removed [38, 39]. Observations from researchers suggest that male partners often accompanied women to the harm reduction services (including prevention, treatment and IEP). The prevalence of intimate partner violence victimisation among female drug users is high [16]; therefore, it is possible that in some cases,

Table 6 EQ-5D-5 $L$ tariff scores at baseline and follow-up

\begin{tabular}{|c|c|c|c|}
\hline & \multicolumn{3}{|l|}{ EQ-5D-5 L tariff score (s.d.) } \\
\hline & Baseline & $\begin{array}{l}\text { End of } \\
\text { intervention }\end{array}$ & 1 month post-intervention \\
\hline Control & $\begin{array}{l}0.617(0.323) \\
N=47\end{array}$ & $\begin{array}{l}0.646(0.314) \\
N=47\end{array}$ & $\begin{array}{l}0.788(0.258) \\
N=47\end{array}$ \\
\hline \multirow[t]{3}{*}{ Intervention } & $\begin{array}{l}0.672(0.247) \\
N=52\end{array}$ & $\begin{array}{l}0.754(0.193) \\
N=52\end{array}$ & $\begin{array}{l}0.775(0.256) \\
N=52\end{array}$ \\
\hline & EQ-5D-5 L changes & & \\
\hline & Baseline to End of intervention & \multicolumn{2}{|c|}{ End of intervention to 1 month post-intervention } \\
\hline Control & $\begin{array}{l}+0.0738(0.216) \\
N=26\end{array}$ & \multicolumn{2}{|l|}{$\begin{array}{l}+0.1420(0.375) \\
N=17\end{array}$} \\
\hline Intervention & $\begin{array}{l}+0.0273(0.233) \\
N=24\end{array}$ & \multicolumn{2}{|l|}{$\begin{array}{l}+0.0369(0.232) \\
N=17\end{array}$} \\
\hline
\end{tabular}


Table 7 Wider health care, criminal justice and societal costs (2014/5 prices) mean cost (s.d.) per patient

\begin{tabular}{|c|c|c|c|c|c|c|}
\hline & \multicolumn{2}{|l|}{ Baseline } & \multicolumn{2}{|c|}{ End of intervention } & \multicolumn{2}{|c|}{1 month post-intervention } \\
\hline & Intervention & Control & Intervention & Control & Intervention & Control \\
\hline Total wider health care Cost & $\begin{array}{l}£ 1109 \\
(1696.14)\end{array}$ & $\begin{array}{l}£ 1257 \\
(2177.61)\end{array}$ & $\begin{array}{l}£ 705 \\
(673.39)\end{array}$ & $\begin{array}{l}£ 997 \\
(786.04)\end{array}$ & $\begin{array}{l}£ 662 \\
(682.47)\end{array}$ & $\begin{array}{l}£ 1466 \\
(2885.66)\end{array}$ \\
\hline Difference between groups & \multicolumn{2}{|c|}{$\begin{array}{l}£ 148 \\
95 \% \text { Cl: }(-657.94,954.54)\end{array}$} & \multicolumn{2}{|c|}{$\begin{array}{l}£ 292 \\
95 \% \mathrm{Cl}:(-137.81,721.34)\end{array}$} & \multicolumn{2}{|c|}{$\begin{array}{l}£ 804 \\
95 \% \mathrm{Cl}:(-611.92,2220.61)\end{array}$} \\
\hline Total criminal justice cost & $\begin{array}{l}£ 1239 \\
(2581.51)\end{array}$ & $\begin{array}{l}£ 1284 \\
(3953.47)\end{array}$ & $\begin{array}{l}£ 439 \\
(2060.80)\end{array}$ & $\begin{array}{l}£ 289 \\
(1348.13)\end{array}$ & $\begin{array}{l}£ 236 \\
(1053.86)\end{array}$ & $\begin{array}{l}£ 521 \\
(1465.97)\end{array}$ \\
\hline Difference between groups & \multicolumn{2}{|c|}{$\begin{array}{l}£ 45 \\
95 \% \mathrm{Cl}:(-1344.95,1434.14)\end{array}$} & \multicolumn{2}{|c|}{$\begin{array}{l}-£ 151 \\
\text { 95\% Cl: }(-1191.45,890.34)\end{array}$} & \multicolumn{2}{|c|}{$\begin{array}{l}£ 285 \\
95 \% \text { Cl: }(-520.06,1091.05)\end{array}$} \\
\hline Total social cost & $\begin{array}{l}£ 2489 \\
(3397.65)\end{array}$ & $\begin{array}{l}£ 2494 \\
(4498.24)\end{array}$ & $\begin{array}{l}£ 1194 \\
(2178.38)\end{array}$ & $\begin{array}{l}£ 1328 \\
(1563.11)\end{array}$ & $\begin{array}{l}£ 908 \\
(1279.79)\end{array}$ & $\begin{array}{l}£ 1909 \\
(3077.46)\end{array}$ \\
\hline Difference between groups & \multicolumn{2}{|c|}{$\begin{array}{l}£ 5 \\
95 \% \mathrm{Cl}:(-2107.85,2117.58)\end{array}$} & \multicolumn{2}{|c|}{$\begin{array}{l}£ 134 \\
95 \% \mathrm{Cl}:(-1034.59,1303.28)\end{array}$} & \multicolumn{2}{|c|}{$\begin{array}{l}£ 1001 \\
95 \% \text { Cl: }(-662.53,2665.44)\end{array}$} \\
\hline
\end{tabular}

male partners prevented women from entering the study. Women-only treatment programmes are recommended and may show improved drug use outcomes [40]; however, interventions and services need to be cognisant of the potential role of intimate partners in accessing treatment.

The proportion attending at least one session in our study was low with just $38 \%$ overall attending at least one session ( $44 \%$ of males and $28 \%$ of females). While our adherence rates are lower than previous trials of behavioural group interventions to address BBV among PWID (range 56-86\%) [41-44], these trials recruited participants entering or engaged in drug treatment which may account for the difference. All of our participants had injected drugs within the past 30 days and $44 \%$ were homeless. Similar to other trials, we found that PWID who were homeless or who injected more frequently were less likely to participate or be followed up [42, 45]. Despite gender-specific sessions being offered [46], women were less likely to attend at least one intervention session than men in our study. Potential reasons for this were previously discussed.

Although the findings suggest that the PROTECT intervention has the potential to positively influence some PWID BBV risk behaviour, non-attendance at the intervention at the York site substantially influenced the results, highlighting the need for flexible delivery of the intervention content to ensure wider reach. Intervention delivery proved more feasible in London than the other sites, with high attendance at the intervention and higher follow-up rates. Participants from Glasgow and York reported higher levels of homelessness, and participants had injected for a greater number of days and used more needles from an IEP, which may have contributed towards lower attendance rates. In addition, text message reminders were sent about session times and dates from the service (reported preference of participants) at the York site; whereas in the other sites, the researcher contacted participants by telephone to remind them a day in advance plus a reminder text on the day. Moreover, staff from the local Clinical Research Network were responsible for recruitment and follow-up of participants (due to researcher leaving); whereas in other sites, participants had contact with the same named researcher throughout, with this established relationship possibly contributing to increased attendance. In addition, reimbursement for travel costs (bus tickets), time and contingency management were paid in cash in the London site versus high street vouchers at the other three sites and peereducators co-facilitated the intervention in the London site only.

Overall, recruitment and retention rates achieved in this feasibility trial lead us to conclude that progression to a full trial is not recommended. There are many factors that may have contributed to the different uptake and retention across sites, and therefore, it is not possible to provide a definitive explanation of the differences in rates reported. However, it appears that the complex needs of many PWID may have limited engagement of those potentially most at risk of engaging in BBV transmission behaviours (e.g. homeless PWID, more frequent injectors, crack use).

The importance of management and of service staff buy-in was stressed by the researchers; presenting the study at staff meetings was used in some settings. In addition, facilitators valued being involved in the development of the intervention. Training of intervention facilitators should be delivered locally (we carried this out centrally in London creating challenges for more distantly located staff) and we recommend that sufficient time be allocated to allow quality assurance of the delivery of the intervention, before the intervention is delivered in practice. Identifying sites that have previously been involved in similar research may facilitate trial implementation as the service will be familiar with what involvement in research studies and trials entails. 
The content of the intervention was rated highly by facilitators and intervention participants alike and there was support for addressing symbiotic goals, planning for risk behaviours and teaching injecting skills to PWID [47-49]. Indeed some intervention participants stressed the need for more practical assistance on injecting technique, including observation and feedback on their own injecting technique. Facilitators felt that the manual could be improved by being more flexible, allowing facilitators to cover the information in each section without having to follow the text verbatim. Both facilitators and participants felt the intervention could be more visual and interactive. Making it available online and including information on novel psychoactive substances was considered a way of making the intervention more relevant and attractive to younger people.

For those participants who attended the intervention sessions, all candidate outcome measures had very good completion rates. The number of injecting risk practices, and self-efficacy in particular, showed improvements in the intervention group that were maintained up to 1 month follow-up. These outcomes might be considered in a larger scale study in the future. BBV transmission knowledge was more likely to show short term improvements only, whereas withdrawal prevention questions had only limited applicability in this study population.

A meta-analysis found that the incidence of $\mathrm{HCV}$ reinfection following successful treatment for HCV among PWID was $2.4 / 100$ per year, and 6.4/100 per year among those who reported injecting drug use post sustained viral response (SVR) [8]. Although there is low risk of reinfection following successful treatment for $\mathrm{HCV}$, a large, cohort study conducted in Scotland found that despite achieving the optimal treatment outcome, a significant minority of PWID continued to inject postSVR at an intensity which lead to either hospitalisation or death and increased risk of reinfection [35]. These findings highlight that "harm reduction interventions aimed at reducing the risk of $\mathrm{HCV}$ transmission should also continue to be promoted once treatment ceases" [50].

\section{Conclusions}

While the intervention showed the potential to positively influence BBV risk behaviours, the findings demonstrate that a future definitive RCT of the PROTECT intervention is not currently feasible in the UK. Despite this, considerable and valuable insight has been obtained showing the need for a greater embedding of BBV risk reduction in the work of substance misuse services and highlights an urgent unmet health need for PWID. Furthermore, the research provides a body of evidence as to how this might best be achieved, and has generated important learning about the feasibility, delivery and implementation of the PROTECT intervention which should inform future studies in the field.

Future studies could consider the use of "chain referral sampling" where existing study participants recruit future participants from among their acquaintances to target participants who may be hidden or difficult to reach for researchers. Participants who assist with the recruitment of other participants would be rewarded for every additional participant they helped recruit. All the participating harm reduction services suggested there was benefit in refining the intervention further by adapting it for delivery in specific settings (e.g. IEP, pharmacy IEP, prison) and to specific groups of PWID including those living in homeless hostels, people receiving opiate substitution therapy, young injectors when they are transferred from adolescent to adult addiction services, steroid injectors, those engaged in chemsex and those injecting novel psychoactive substances.

\section{Additional files}

Additional file 1: Participant characteristics by compliance (Total). (DOCX $14 \mathrm{~kb}$ )

Additional file 2: Participant characteristics by recruitment Site. (DOCX $15 \mathrm{~kb}$ )

\section{Abbreviations}

BBV: Blood-borne viruses; EQ-5D-5L: European quality of life-5 dimensions-5 levels version; HBV: Hepatitis B virus; HCV: Hepatitis C virus; HIV: Human immunodeficiency virus; HRQOL: Health-related quality of life; IEP: Injecting equipment provision; PWID: People who inject drugs; QALY: Quality adjusted life year; TAU: Treatment as usual

\section{Acknowledgements}

We are grateful to the staff and service users at the substance use treatment services where the study took place. We would like to thank officers and research nurses from the Clinical Research Network: South London (Michael Kelly and Amy McLachlan), York Teaching Hospitals NHS Trust (Christopher Rhymes, Andy Gibson, Monica Wright and Zoe Coleman) and Clinical Research Network: Wales (Lynda Sackett) for their help with recruitment and assessment of participants to the feasibility trial. We would also like to thank Zoe Richardson (University of York) for conducting the staff focus groups in York and for data entry, and Dr Martha Canfield (King's College London) for assisting with the collection of outcome data for the feasibility trial in London. We would also like to thank the PROTECT intervention development group: Stephanie Brickwood, Archie Christian, Jon Derricott, John Dillon, Paul Donachy, Magdalena Harris, Paul Lennon, Martin McCusker, Luke Mitcheson, Danny Morris, Terry Shields, Josie Smith, Carla Treloar and Jason Wallace.

This manuscript presents independent research funded by the National Institute for Health Research (NIHR) under the Health Technology Assessment programme [project number 13/17/04]. The findings from this review will also be published as part of the full project report "Preventing blood borne virus infection in people who inject drugs in the UK: the development and feasibility of psychosocial interventions" in Health Technology Assessment. The views expressed in this publication are those of the authors and not necessarily those of the NHS, the NIHR or the Department of Health.

\section{Funding}

This project was funded by the National Institute for Health Research Health Technology Assessment programme (project number 13/17/04). The views and opinions expressed therein are those of the authors and do not necessarily reflect those of the Health Technology Assessment programme, NIHR, NHS or the Department of Health. 


\section{Availability of data and materials}

The datasets analysed during the current study are available from the corresponding author on reasonable request. The PROTECT manual is available for download via: https://www.kcl.ac.uk/ioppn/depts/addictions/ research/drugs/bloodborneviruses.aspx

\section{Authors' contributions}

GG led on the design of all phases of the research, developed the protocol for the feasibility study, led the intervention development, had overall responsibility for the conduct of all phases of the research and was a major contributor in writing the manuscript. DS was responsible for the day-to-day running of the research in London. She collected data for all phases of the research and was a major contributor in writing the manuscript. AS conducted the study and collected the data at the Glasgow site and was a major contributor in writing the manuscript. AK was responsible for the statistical analysis for the feasibility trial and was a major contributor in writing the manuscript. ST conducted the study and collected the data at the Wales site. NC was responsible for the day-to-day running of the research in Wales and was a contributor in writing the manuscript. AM was responsible for the day-to-day running of the research in Glasgow and was a major contributor in writing the manuscript. EH was responsible for the day-to-day running of the research in York was a major contributor in writing the manuscript. SP was responsible for the health economics component of the feasibility trial and was a contributor in writing the manuscript. cpfS contributed to the design of all phases of the research and contributed to writing the manuscript. AT contributed to the design of all phases of the research and contributed to writing the manuscript. JW was responsible for day-to-day trial management and the development of the feasibility trial protocol and was a major contributor in writing the manuscript. All authors read and approved the final manuscript.

\section{Competing interests}

The authors declare that they have no competing interests. JS's employer (King's College London) has received, unconnected to the area covered in this study but connected to his wider work, research grant support and/or payment of honoraria, consultancy payments and/or travelling and/or accommodation and/or conference expenses from pharmaceutical companies (including, past 3 years, Martindale, Indivior, MundiPharma, Braeburn) with whom he has discussed medications potentially applicable in the treatment of addictions and related problems. For updated information see http://www.kcl.ac.uk/ioppn/ depts/addictions/people/hod.aspx

\section{Consent for publication}

Not applicable.

\section{Ethics approval and consent to participate}

The study was granted ethical approval by the National Research Ethics Committee East Midlands-Leicester South Research Ethics Committee (Reference: 15/EM/0413). Local Research and Development (R\&D) approval was obtained as well as agreement to participate from the relevant services.

\section{Publisher's Note}

Springer Nature remains neutral with regard to jurisdictional claims in published maps and institutional affiliations.

\footnotetext{
Author details

'Institute of Psychiatry, Psychology and Neuroscience, King's College London, Addictions Sciences Building, 4 Windsor Walk, Denmark Hill, London SE5 8BB, England, UK. ${ }^{2}$ School of Media, Culture \& Society, University of the West of Scotland, Paisley Campus, High Street, Paisley PA1 2BE, Scotland, UK. ${ }^{3}$ York Trials Unit, Department of Health Sciences, University of York, Heslington, York YO10 5DD, England, UK. ${ }^{4}$ Betsi Cadwaladr University Hospital Trust, 10 Grove Road, Wrexham LL11 1DY, Wales, UK. ${ }^{5}$ Public Health Wales, Microbiology Department, Ysbyty Gwynedd, Bangor, Gwynedd LL57 2PW, Wales, UK. ${ }^{6}$ School of Health and Human Sciences, University of Huddersfield, Queensgate, Huddersfield, West Yorkshire HD1 3DH, England, UK. ${ }^{7}$ Department of Health Sciences, University of York, Heslington, York YO10 $5 \mathrm{DD}$, England, UK.
}

Received: 18 October 2016 Accepted: 10 March 2017 Published online: 21 March 2017

\section{References}

1. Hahné SJ, Veldhuijzen IK, Wiessing L, Lim TA, Salminen M, van de Laar M. Infection with hepatitis B and C virus in Europe: a systematic review of prevalence and cost-effectiveness of screening. BMC Infect Dis. 2013;13(1):1.

2. Mathers BM, Degenhardt L, Phillips B, Wiessing L, Hickman M, Strathdee SA, Wodak A, Panda S, Tyndall M, Toufik A, Mattick RP. Global epidemiology of injecting drug use and HIV among people who inject drugs: a systematic review. Lancet. 2008;372(9651):1733-45.

3. Public Health England, National Infection Service. Unlinked anonymous monitoring survey of people who inject drugs: data tables. London: Public Health England; 2015.

4. Palmateer N, Hutchinson S, McAllister G, Munro A, Cameron S, Goldberg D, et al. Risk of transmission associated with sharing drug injecting paraphernalia: analysis of recent hepatitis C virus ( $\mathrm{HCV}$ infection using cross-sectional survey data. J Viral Hepat. 2014;21:25-32. http://dx.doi.org/10.1111/jvh.12117.

5. Corson S, Greenhalgh D, Taylor A, Palmateer N, Goldberg D, Hutchinson S Modelling the prevalence of HCV amongst people who inject drugs: an investigation into the risks associated with injecting paraphernalia sharing. Drug Alcohol Depend. 2013;133:172-9. http://dx.doi.org/10.1016/j. drugalcdep.2013.05.014.

6. Grant RM. Antiretroviral agents used by HIV-uninfected persons for prevention: pre-and postexposure prophylaxis. Clin Infect Dis. 2010; 50(Supplement 3):S96-101.

7. Baeten J, Celum C. Systemic and topical drugs for the prevention of HIV infection: antiretroviral pre-exposure prophylaxis. Annu Rev Med. 2013;64:219.

8. Aspinall EJ, Corson S, Doyle JS, Grebely J, Hutchinson SJ, Dore GJ, Goldberg DJ, Hellard ME. Treatment of hepatitis C virus infection among people who are actively injecting drugs: a systematic review and meta-analysis. Clin Infect Dis. 2013;57 suppl 2:580-9.

9. Turner KM, Hutchinson S, Vickerman P, Hope V, Craine N, Palmateer N, et al. The impact of needle and syringe provision and opiate substitution therapy on the incidence of hepatitis $C$ virus in injecting drug users: pooling of UK evidence. Addiction. 2011;106:1978-88.

10. Degenhardt L, Mathers B, Vickerman P, Rhodes T, Latkin C, Hickman M. Prevention of HIV infection for people who inject drugs: why individual, structural, and combination approaches are needed. Lancet. 2010;376:285-301.

11. MacArthur GJ, van Velzen E, Palmateer N, Kimber J, Pharris A, Hope V, et al. Interventions to prevent HIV and Hepatitis $C$ in people who inject drugs: a review of reviews to assess evidence of effectiveness. Int J Drug Policy. 2014;25:34-52.

12. Aspinall EJ, Nambiar D, Goldberg DJ, Hickman M, Weir A, Van Velzen E, et al. Are needle and syringe programmes associated with a reduction in HIV transmission among people who inject drugs: a systematic review and meta-analysis. Int J Epidemiol. 2014;43:235-48.

13. O'Brien S, Day C, Black E, Dolan K. Injecting drug users' understanding of hepatitis C. Addict Behav. 2008;33:1602-5. http://dx.doi.org/10.1016/j. addbeh.2008.07.005

14. Cohen-Moreno R, Schiff M, Levitt S, Bar-Hamburger R, Strauss S, Neumark Y. Knowledge about hepatitis $\mathrm{C}$ among methadone maintenance treatment patients in Israel. Subst Use Misuse. 2010;45:58-76.

15. Treloar C, Hull P, Bryant J, Hopwood M, Grebely J, Lavis Y. Factors associated with hepatitis $C$ knowledge among a sample of treatment naive people who inject drugs. Drug Alcohol Depend. 2011;116:52-6.

16. Gilchrist G, Blazquez A, Torrens M. Psychiatric, behavioural and social risk factors in HIV infection among female drug users. AIDS Behav. 2011;15: 1834-43. http://dx.doi.org/10.1007/s10461-011-9991-1.

17. Strathdee SA, Galai N, Safaiean M, Celentano DD, Vlahov D, Johnson L, et al. Sex differences in risk factors for HIV seroconversion among injection drug users: a 10-year perspective. Arch Intern Med. 2001;161:1281-8.

18. Gilchrist $G$, Singleton N, Donmall M, Jones A. Prevalence and factors associated with sex trading in the year prior to entering treatment for drug misuse in England. Drug Alcohol Depend. 2015;152:116-22.

19. Disney E, Kidorf M, Kolodner K, King V, Peirce J, Beilenson P, et al. Psychiatric comorbidity is associated with drug use and HIV risk in syringe exchange participants. J Nerv Ment Dis. 2006;194:577-83.

20. Public Health England, Health Protection Scotland, Public Health Wales, and Public Health Agency Northern Ireland. Shooting up: infections among people who inject drugs in the United Kingdom 2015. An update 
November 2016. London, Public Health England. https:/www.gov.uk/ government/uploads/system/uploads/attachment_data/file/567231/ Shooting_Up_2016_Update.pdf. Accessed 30 Jan 2017.

21. Hope VD, Cullen KJ, Smith J, Jessop L, Parry J, Ncube F. Is the recent emergence of mephedrone injecting in the United Kingdom associated with elevated risk behaviours and blood borne virus infection? Euro Surveill. 2016;21(19).

22. Hagan $H$, Pouget ER, Des Jarlais DC. A systematic review and meta-analysis of interventions to prevent hepatitis C virus infection in people who inject drugs. J Infect Dis. 2011;204:74-83.

23. Meader N, Li R, Des Jarlais DC, Pilling S. Psychosocial interventions for reducing injection and sexual risk behaviour for preventing HIV in drug users. Cochrane Database Syst Rev. 2010;1, CD007192. http://dx.doi.org/10. 1002/14651858.CD007192.pub2.

24. Sacks-Davis R, Horyniak D, Grebely J, Hellard M. Behavioural interventions for preventing hepatitis $\mathrm{C}$ infection in people who inject drugs: a global systematic review. Int J Drug Policy. 2012;23:176-84.

25. Purcell DW, Latka MH, Metsch LR, Latkin CA, Gómez CA, Mizuno Y, et al. Results from a randomized controlled trial of a peer-mentoring intervention to reduce HIV transmission and increase access to care and adherence to HIV medications among HIV-seropositive injection drug users. J Acquir Immune Defic Syndr. 2007;46 Suppl 2:S35-47.

26. Vazan P, Mateu-Gelabert P, Cleland CM, Sandoval M, Friedman SR. Correlates of staying safe behaviors among long-term injection drug users: psychometric evaluation of the staying safe questionnaire. AIDS Behav. 2012;16:1472-81.

27. Carey MP, Schroder KE. Development and psychometric evaluation of the brief HIV Knowledge Questionnaire. AIDS Educ Prev. 2002;14:172-82.

28. Gilchrist G, Taylor A, Fischer G, Moskalewicz J. Di Furia L, Köchl B, Giammarchi C, Dąbrowska K, Shaw A, Munro A, Torrens M. Feasibility of a psychosocial group intervention to reduce hepatitis $C$ risk behaviours and increase transmissionknowledge among females who inject drugs in 5 European cities. Drugs, Education, Prevention and Policy. 2017;24(2):179-88. http://www.tandfonline.com/doi/full/10.1080/09687637.2016.1197885.

29. Balfour L, Kowal J, Corace KM, Tasca GA, Krysanski V, Cooper CL, et al. Increasing public awareness about hepatitis C: development and validation of the brief hepatitis C knowledge scale. Scand J Caring Sci. 2009;23:801-8.

30. Hajarizadeh B, Wallace J, Richmond J, Ngo N, Enright C. Hepatitis B knowledge and associated factors among people with chronic hepatitis B. Aust N Z J Public Health. 2015;39:563-8.

31. Rabin R, de Charro F. EQ-5D: a measure of health status from the EuroQol group. Ann Med. 2001;33:337-43.

32. Lancaster GA, Dodd S, Williamson PR. Design and analysis of pilot studies: recommendations for good practice. J Eval Clinl Pract. 2004;10:307-12.

33. Julious SA. Sample size of 12 per group rule of thumb for a pilot study. Pharm Stat. 2005;4:287-91.

34. Arain M, Campbell MJ, Cooper CL, Lancaster GA. What is a pilot or feasibility study? A review of current practice and editorial policy. BMC Med Res Methodol. 2010;10:67.

35. National Institute for Health and Clinical Excellence. Drug misuse: psychosocial interventions. London: National Institute for Health and Clinical Excellence; 2007.

36. Van Hout B, Janssen MF, Feng YS, Kohlmann T, Busschbach J, Golicki D, Lloyd A, Scalone L, Kind P, Pickard AS. Interim scoring for the EQ-5D-5L: mapping the EQ-5D-5L to EQ-5D-3L value sets. Value Health. 2012;15(5):708-15.

37. Craine N, Hickman M, Parry JV, Smith J, McDonald T, Lyons M. Characteristics of injecting drug users accessing different types of needle and syringe programme or using secondary distribution. J Public Health. 2010;32:328-35.

38. Brady TM, Ashley OS. Women in substance abuse treatment: results from the alcohol and drug services study (ADSS). Vol. Analytic Series A-26. Rockville: Substance Abuse and Mental Health Services Administration, Office of Applied Studies: DHHS Pub. No. SMA 04-3968; 2005.

39. Powis B, et al. Drug-using mothers: social, psychological and substance use problems of women opiate users with children. Drug Alcohol Rev. 2000;19:171-80.

40. Ashley OS, Marsden ME, Brady TM. Effectiveness of substance abuse treatment programming for women: a review. Am J Drug Alcohol Abuse. 2003;29(1):19-53.

41. Avants SK, Margolin A, Usubiaga MH, Doebrick C. Targeting HIV-related outcomes with intravenous drug users maintained on methadone: a randomized clinical trial of a harm reduction group therapy. J Subst Abuse Treat. 2004;26(2):67-78.
42. Garfein RS, Golub ET, Greenberg AE, Hagan H, Hanson DL, Hudson SM, ... \& DUIT Study Team., A peer-education intervention to reduce injection risk behaviors for HIV and hepatitis C virus infection in young injection drug users. Aids. 2007;21(14):1923-132.

43. Latka MH, Hagan H, Kapadia F, Golub ET, Bonner S, Campbell JV, Coady MH, Garfein RS, Pu M, Thomas DL, Thiel TK, Strathdee SA. A randomized intervention trial to reduce the lending of used injection equipment among injection drug users infected with hepatitis C. Am J Public Health. 2008; 98(5):853-61.

44. Margolin A, Avants SK, Warburton LA, Hawkins KA, Shi J. A randomized clinical trial of a manual-guided risk reduction intervention for HIV-positive injection drug users. Health Psychol. 2003;22(2):223-8.

45. Booth RE, Campbell BK, Mikulich-Gilbertson SK, Tillotson CJ, Choi D, Robinson J, Calsyn DA, Mandler RN, Jenkins LM, Thompson LL, Dempsey CL, Liepman MR, McCarty D. Reducing HIV-related risk behaviors among injection drug users in residential detoxification. AIDS Behav. 2011;15(1):3044.

46. Green CA. Gender and use of substance abuse treatment services. Alcohol Res Health. 2006;29(1):55-62.

47. Harris M, Rhodes T. Venous access and care: harnessing pragmatics in harm reduction for people who inject drugs. Addiction. 2012;107(6):1090-6.

48. Harris M, Treloar C, Maher L. Staying safe from hepatitis C: engaging with multiple priorities. Qual Health Res. 2012;22:31-42.

49. Mateu-Gelabert P, Gwadz MV, Guarino H, Sandoval M, Cleland CM, Jordan A, ... \& Friedman SR. The staying safe intervention: training people who inject drugs in strategies to avoid injection-related HCV and HIV infection. AIDS Educ Prev. 2014; 26(2):144.

50. Valerio H, Goldberg DJ, Lewsey J, Weir A, Allen S, Aspinall EJ, Barclay ST, Bramley P, Dillon JF, Fox R, Fraser A, Hayes PC, Innes H, Kennedy N, Mills PR, Stanley AJ, Hutchinson SJ. Evidence of continued injecting drug use after attaining sustained treatment-induced clearance of the hepatitis $C$ virus: implications for reinfection. Drug Alcohol Depend. 2015;154:125-31.

\section{Submit your next manuscript to BioMed Central and we will help you at every step:}

- We accept pre-submission inquiries

- Our selector tool helps you to find the most relevant journal

- We provide round the clock customer support

- Convenient online submission

- Thorough peer review

- Inclusion in PubMed and all major indexing services

- Maximum visibility for your research

Submit your manuscript at www.biomedcentral.com/submit
Biomed Central 